\title{
O PROBLEMA DA INFLAÇÃo DE DIREITOS: CAUSAS E RISCOS
}

\author{
THE PROBLEM OF RIGHTS INFLATION: CAUSES AND RISKS
}

André Gualtieri ${ }^{1}$

\section{RESUMO}

Este artigo aborda a inflação de direitos como resultado do surgimento do conceito de autonomia individual na modernidade. Por meio de pesquisa bibliográfica e utilizando-se do método indutivo, o artigo analisa o processo inflacionário pelo qual o direito moderno vem passando. São identificados dois sentidos do conceito de inflação de direitos e se propõe que, no Brasil, ele seja compreendido como um processo de incessante proliferação de direitos e de judicialização de vidas. 0 princípio da proporcionalidade exerce um papel importante nesse processo. 0 trabalho aponta as razões pelas quais a inflação de direitos seria um problema e os riscos que ela traz para o Direito enquanto sistema, para os direitos fundamentais e para o princípio da dignidade da pessoa humana.

PALAVRAS-CHAVE: inflação de direitos; autonomia individual; sistema; direitos fundamentais; dignidade da pessoa humana.

\section{ABSTRACT}

This article addresses the inflation of rights as a result of the emergence of the concept of individual autonomy in modern times. Through bibliographic research and using the inductive method, the article analyzes the inflationary process that modern law has been going through. Two meanings of the concept of inflation of rights are identified and it is proposed that, in Brazil, it be understood as a process of incessant proliferation of rights and judicialization of lives. The principle of proportionality plays an important role in this process. The work points out the reasons why inflation of rights would be a problem and the risks it brings to law as a system, to fundamental rights and to the principle of human dignity.

KEYWORDS: rights inflation; individual autonomy; system; fundamental rights; dignity of human person.

\footnotetext{
${ }^{1}$ Doutorando em Teoria e Filosofia do Direito pela Pontifícia Universidade Católica de São Paulo, SP, Brasil. Professor na Universidade Cruzeiro do Sul, São Paulo. Esta pesquisa é financiada por uma bolsa concedida pela Coordenação de Aperfeiçoamento de Pessoal de Nível Superior (CAPES). Email: andregualtierioliveira@gmail.com
} 
GUALTIERI, André. O problema da inflação de direitos: causas e riscos. Revista Eletrônica Direito e Política, Programa de Pós-Graduação Stricto Sensu em Ciência Jurídica da UNIVALI, Itajaí, v.16, n.1, $1^{\circ}$ quadrimestre de 2021. Disponível em: www.univali.br/direitoepolitica - ISSN 1980-7791

\section{INTRODUÇÃO}

A modernidade é a era dos direitos. Uma das características mais notáveis do nosso tempo é a possibilidade de que uma infinidade de temas, interesses e reivindicações se transformem em direitos. Do final do século XVIII em diante, gerações ou dimensões de direitos fundamentais foram sucessivamente surgindo, cada uma delas se desenvolvendo a partir de novos problemas. A cultura, por exemplo, que no passado era simplesmente adquirida através do contato com as tradições de um povo, tornou-se, em nosso tempo, um direito.

Os direitos fundamentais têm como uma de suas características a historicidade ${ }^{2}$, pois são o resultado de um desenvolvimento histórico que não conhece fim, sendo, por conseguinte, inexauríveis, já que novos direitos poderão sempre surgir, a fim de lidar com novos aspectos relativos às necessidades humanas. Uma série de direitos são apontados pela doutrina como a mais nova fronteira dos direitos fundamentais, dentre eles estão os direitos ao desenvolvimento, à paz, à comunicação, à qualidade de vida e à integridade do patrimônio genético ${ }^{3}$.

Como observa Lynn Hunt ${ }^{4}$, a lógica dos direitos humanos, desde o seu início, revela uma tendência de que eles se sucedam em cascata, ou seja, novos direitos estão sempre surgindo, abraçando pessoas e questões que não foram alcançadas anteriormente. Já em 1776, John Adams, numa carta escrita a James Sullivan, juiz da Corte Suprema de Massachusetts, afirmava: "Isso não terminará nunca. Surgirão novas reivindicações". ${ }^{5}$

É nesse sentido que utilizarei o termo inflação de direitos nesse trabalho, isto é, como um processo contínuo e incessante de criação de direitos, produzindo um resultado cumulativo, pois a lista de direitos torna-se sempre maior.

Muitos dos avanços que ocorreram no mundo nos últimos dois séculos têm sido ligados ao processo de expansão dos direitos humanos, a nível internacional, e dos

\footnotetext{
2 BRANCO, Paulo Gustavo Gonet; MENDES, Gilmar Ferreira. Curso de direito constitucional. 11 ed. São Paulo: Saraiva, 2016, p. 142.

3 BOBBIO, Norberto. A era dos direitos. Rio de Janeiro: Campus, 1992, p. 12.

4 HUNT, Lynn. A invenção dos direitos humanos: uma história. São Paulo: Companhia das Letras, 2009, p. 1862.

${ }^{5}$ HUNT, Lynn. A invenção dos direitos humanos: uma história. p. 1867.
} 
GUALTIERI, André. O problema da inflação de direitos: causas e riscos. Revista Eletrônica Direito e Política, Programa de Pós-Graduação Stricto Sensu em Ciência Jurídica da UNIVALI, Itajaí, v.16, n.1, 10 quadrimestre de 2021. Disponível em: www.univali.br/direitoepolitica - ISSN 1980-7791

direitos fundamentais, consagrados pelas Constituições dos mais diversos países. A Declaração Universal dos Direitos Humanos de 1948, por exemplo, expressou anseios profundos entre homens e mulheres em todos os lugares, fortalecendo os movimentos que acabariam com o colonialismo, o apartheid e a Cortina de Ferro; contribuiu para o surgimento de regimes democráticos inicialmente na Europa e depois na América Latina, África e Ásia; inspirou legiões de ativistas e deu aos membros mais fracos da sociedade um instrumento para ampliar suas vozes. ${ }^{6}$

No Brasil, a Constituição de 1988 instituiu um amplo rol de direitos fundamentais, estabelecendo um alto grau de proteção das liberdades individuais e criando uma importante teia de proteção social, determinante para o desenvolvimento da sociedade brasileira nas décadas seguintes, da qual fazem parte, por exemplo, o SUS e a Defensoria Pública.

Mas seria possível apontar também efeitos problemáticos na constante expansão de direitos? Este trabalho pretende mostrar que (i) a inflação é um problema para qualquer ordenamento jurídico; (ii) no Brasil, esse processo inflacionário se dá tanto pela atividade legislativa quanto por obra do poder judiciário e que, quando acontece no âmbito deste poder, ocorre tanto em razão da chamada judicialização quanto do princípio da proporcionalidade.

Para isso será utilizada pesquisa bibliográfica de obras de autores nacionais e internacionais. Além disso, a análise será realizada a partir do método indutivo, pois, da observação dos diferentes ordenamentos jurídicos do ocidente, é possível identificar uma tendência inflacionária geral em matéria de direitos.

A fim de desenvolver de modo mais detalhado a problemática do fenômeno inflacionário no direito, analisarei os motivos que levaram a uma proliferação aparentemente sem fim de direitos. Em seguida, abordarei alguns riscos que a inflação poderia trazer ao sistema jurídico e algumas propostas sobre como lidar com esse problema.

6 GLENDON, Mary Ann; KAPLAN, Seth D. Renewing human rights. First Things. Fev. 2019. Disponível em: https://www.firstthings.com/article/2019/02/renewing-human-rights. Acesso em: 20 mar. 2020. 
GUALTIERI, André. O problema da inflação de direitos: causas e riscos. Revista Eletrônica Direito e Política, Programa de Pós-Graduação Stricto Sensu em Ciência Jurídica da UNIVALI, Itajaí, v.16, n.1, 10 quadrimestre de 2021. Disponível em: www.univali.br/direitoepolitica - ISSN 1980-7791

Um aspecto essencial da dinâmica dos direitos humanos é a existência de um potencial inesgotável para a criação de novos direitos. As raízes disso estão numa antropologia filosófica notadamente moderna, cuja concepção de natureza humana enxerga no desejo uma fonte inesgotável de geração do direito. Porém, como o desejo é inextinguível, teríamos, como reflexo, o que testemunhamos contemporaneamente: "a tendência de definir qualquer coisa desejável como um direito", como observa Michael Ignatieff. ${ }^{7}$ Isso leva ao problema da inflação de direitos.

\section{AS BASES DO PROCESSO INFLACIONÁRIO DO DIREITO MODERNO}

O conceito de direito subjetivo é um conceito moderno e está fundado na noção de indivíduo, que reflete os elementos constitutivos do tipo de cultura que vinha se formando no ocidente desde o fim da Idade Média e acabou por se consolidar a partir do século XVI, inaugurando a era moderna.

O individualismo ocidental, sem o qual não seria possível o conceito de direito subjetivo, "surgiu do dualismo medieval entre Estado e Igreja, de onde logo se separaram também as exigências autônomas vindas do setor econômico". ${ }^{8} \mathrm{O}$ teólogo franciscano Guilherme de Ockham, no contexto da querela franciscana com o Papado sobre a pobreza apostólica, contribuiu decisivamente para o surgimento do conceito de direito subjetivo ao deslocar a abordagem sobre o direito da ontologia para a sua significação. ${ }^{9}$

É a partir desse conceito fundamental de direito subjetivo que o pensamento jurídico moderno se desenvolveu. Os direitos humanos ou, no contexto de um ordenamento jurídico nacional, direitos fundamentais, são justamente direitos subjetivos consagrados constitucionalmente.

\footnotetext{
7 IGNATIEFF, Michael. Human rights as idolatry. THE TANNER LECTURES ON HUMAN VALUES, 2000. Disponível em: https://tannerlectures.utah.edu/ documents/a-to-z/i/Ignatieff 01.pdf. Acesso em: 28 abr. 2020, p. 346.

8 LUHMANN, Niklas. Introdução à teoria dos sistemas. Petrópolis: Vozes, 2009, p. 252.

${ }^{9}$ GUERRA FILHO, Willis Santiago. O conhecimento imaginário do direito. 1 ed. Curitiba: Editora Prismas, 2017, p. 66.
} 
GUALTIERI, André. O problema da inflação de direitos: causas e riscos. Revista Eletrônica Direito e Política, Programa de Pós-Graduação Stricto Sensu em Ciência Jurídica da UNIVALI, Itajaí, v.16, n.1, 10 quadrimestre de 2021. Disponível em: www.univali.br/direitoepolitica - ISSN 1980-7791

Em fins do século XVIII, já não se podia mais pensar no direito moderno sem uma Constituição. Toda sociedade que se pretendia moderna deveria possuir uma Constituição, formada por normas que estabelecessem direitos fundamentais e separação de poderes. A Declaração dos Direitos do Homem e do Cidadão de 1789, em seu art. 16, afirmava: "Qualquer sociedade em que não esteja assegurada a garantia dos direitos, nem estabelecida a separação dos poderes não tem Constituição." 10

Inicialmente, os direitos humanos visavam proteger o indivíduo do abuso do poder estatal. Algum tempo depois, apareceram aqueles direitos ligados à promoção da igualdade, que buscavam dotar cada pessoa de um conjunto de recursos básicos sem os quais elas não poderiam se desenvolver como indivíduos livres. Esse processo contínuo de crescimento continua até nossos dias. Toda sociedade moderna, portanto, está construída sobre um Estado de Direito. Daí porque o direito ocupa um lugar central no nosso tempo. ${ }^{11}$

Assim, a Constituição surge como o elemento propriamente moderno de organização social. Durante toda a história humana, a estabilidade social dependeu da religião, único elemento capaz de unificar os indivíduos em comunidade. A modernidade, porém, é secular. Nela é a Constituição e não mais, por exemplo, a ortodoxia católica o elemento em torno do qual as pessoas se reúnem. Como afirma John Rawls:

As doutrinas religiosas, que em séculos anteriores formavam a base reconhecida da sociedade, foram aos poucos cedendo o lugar a princípios constitucionais de governo que todos os cidadãos, qualquer que seja sua visão religiosa, podem endossar. Doutrinas filosóficas e morais abrangentes tampouco podem ser endossadas pelos cidadãos em geral, e já não podem mais, se é que puderam algum dia, constituir-se na base reconhecida da sociedade. ${ }^{12}$

Esse direito moderno é o resultado de uma visão de mundo que tem como aspecto central o indivíduo e suas vontades. Isso acaba atribuindo ao desejo o papel de

10 FRANÇA. [Declaração de direitos do homem e do cidadão (1789)]. Disponível em: http://www.direitoshumanos.usp.br/index.php/Documentos-anteriores-\%C3\%A0cria\%C3\%A7\%C3\%A3o-da-Sociedade-das-Na\%C3\%A7\%C3\%B5es-at\%C3\%A9-1919/declaracaode-direitos-do-homem-e-do-cidadao-1789.html. Acesso em: 28 fev. 2020.

${ }^{11}$ HERRERO, Francisco Javier. Estudos de ética e filosofía da religião. São Paulo: Loyola, 2006.

12 RAWLS, John. O liberalismo político. 2. ed. São Paulo: Editora Atica, 2000, p. 52. 
GUALTIERI, André. O problema da inflação de direitos: causas e riscos. Revista Eletrônica Direito e Política, Programa de Pós-Graduação Stricto Sensu em Ciência Jurídica da UNIVALI, Itajaí, v.16, n.1, 10 quadrimestre de 2021. Disponível em: www.univali.br/direitoepolitica - ISSN 1980-7791

fonte a partir da qual novas normas devem surgir. Na medida em que o direito passa a ser pensado como algo cuja origem é o indivíduo e suas vontades, isso vincula a criação normativa ao ingovernável e ilimitado desejo humano, dando início a um processo incessante de normatização da vida. O processo inflacionário de direitos em nossa época tornou-se possível graças a isso.

O pensamento de Thomas Hobbes foi determinante no estabelecimento do paradigma político e jurídico da modernidade. Hobbes é considerado "o fundador da tradição moderna dos direitos individuais, o primeiro filósofo a substituir completamente o conceito de justiça pela ideia de direitos". ${ }^{13}$ Há com isso o surgimento de um novo modelo de direito, baseado numa nova concepção moderna - de natureza humana defendida por Hobbes. Para ele,

O homem não é mais concebido como um espelho de alguma realidade externa e superior, mas como uma lâmpada, a fonte e o centro da luz que ilumina o mundo. O Ser não é mais a criação de uma primeira causa divina (...) O homem é poiético, sua essência está no fazer e no movimento, torna-se criador e causa de ações e portador de significado em uma realidade profana. ${ }^{14}$

Na teoria hobbesiana, temos uma noção de natureza humana na qual o sujeito é o criador de sua realidade conforme seu próprio desejo. Para Hobbes, o homem em seu estado natural é movido pelo desejo, o que também leva ao medo, pois quando as pessoas se relacionam, temos indivíduos com desejos conflitantes. Assim, a condição social natural da humanidade é a guerra, que, embora não explícita, aparece como um estado perpétuo de preparação ansiosa para o conflito. Medo, ignorância e desejo são o que move toda atividade humana. ${ }^{15}$

Assim, com base na ideia de liberdade como ausência de impedimentos externos, Hobbes propõe um conceito de direito natural entendido como

a liberdade de cada homem para usar seu próprio poder da forma que desejar para a preservação de sua própria Natureza; isto é, de sua própria Vida; e consequentemente, de fazer qualquer coisa que

\footnotetext{
13 DOUZINAS, Costas. The end of human rights: critical legal thought at the turn of the century. Oxford: Hart Publishing, 2000, p. 69.

${ }_{14}$ DOUZINAS, Costas. The end of human rights: critical legal thought at the turn of the century. p. 73.

${ }^{15}$ LILLA, Mark. The stillborn god: religion, politics and the modern west. New York: Vintage Books, 2007.
} 
GUALTIERI, André. O problema da inflação de direitos: causas e riscos. Revista Eletrônica Direito e Política, Programa de Pós-Graduação Stricto Sensu em Ciência Jurídica da UNIVALI, Itajaí, v.16, n.1, 10 quadrimestre de 2021. Disponível em: www.univali.br/direitoepolitica - ISSN 1980-7791

conceba em seu próprio julgamento e em sua própria Razão como sendo o meio mais adequado para tal fim. ${ }^{16}$

Por natureza, portanto, todo homem tem direito a tudo. Esse direito natural deriva da nossa capacidade de desejar, que é o que torna possível possuir ou desfrutar algo. ${ }^{17}$ Mas isso só dura enquanto houver a guerra de todos contra todos, que é o estado natural do homem. Quando se põe um fim nisso, os homens ficam submetidos à lei segundo a qual

Quando um homem acreditar serem necessárias a Paz e a autodefesa, ele deve, por vontade própria e dos outros homens, renunciar ao seu direito de possuir tudo; e ficar satisfeito em ter, contra os outros homens, a mesma medida de liberdade que ele permitiria que os outros tivessem contra ele mesmo. ${ }^{18}$

O fenômeno da inflação de direitos é resultado do estabelecimento dessa noção de direito baseada no indivíduo, sua autonomia e seu desejo. O modelo liberal que surge daí se baseia em dois pontos fundamentais: o indivíduo livre e o Estado que o controla. Mas a ironia deste processo está no fato de que, quanto mais se busca assegurar a autonomia individual, maior também se torna o Estado, por meio das normas que este tem que criar para promover aquela.

Cria-se uma situação paradoxal, pois quanto mais o indivíduo - livre - busca concretizar os desejos nascidos de sua autonomia, mais ele necessita se sujeitar ao Estado de Direito. ${ }^{19}$ Isso gera um ambiente inflacionário, pois com o fim do estado de natureza e a instauração do estado civil, o único meio de garantir que o indivíduo tenha o que quer é por intermédio do direito.

Assim, é significativo que Jhering, no século XIX, tenha definido o direito subjetivo como o interesse juridicamente protegido. ${ }^{20}$ Isso é uma clara consequência da

\footnotetext{
16 HOBBES, Thomas. Leviatã: ou matéria, forma e poder de um Estado eclesiástico e civil. São Paulo: Edipro, 2015, p. 121.

17 TUCK, Richard. Natural rights theories: their origin and development. Cambridge: Cambridge University Press, 1998.

${ }^{18}$ HOBBES, Thomas. Leviatã: ou matéria, forma e poder de um Estado eclesiástico e civil. p. 122.

19 DENEEN, Patrick J. Why liberalism failed. New Haven: Yale University Press, 2018.

${ }^{20}$ FERRAZ JR., Tercio Sampaio. Introdução ao estudo do direito: técnica, decisão, dominação.

2 ed. São Paulo: Atlas, 1994, p. 149.
} 
GUALTIERI, André. O problema da inflação de direitos: causas e riscos. Revista Eletrônica Direito e Política, Programa de Pós-Graduação Stricto Sensu em Ciência Jurídica da UNIVALI, Itajaí, v.16, n.1, 10 quadrimestre de 2021. Disponível em: www.univali.br/direitoepolitica - ISSN 1980-7791

fundamentação do direito a partir do desejo. Direito e interesse passam a caminhar juntos.

A teoria moderna também busca separar o direito das esferas da ética e da política. Enquanto os clássicos as pensavam como uma unidade, entre os modernos passa a ser importante estabelecer cada uma delas como uma área autônoma. Isso se tornou possível devido à elaboração da noção de direito como sistema, que funciona ao lado de outros sistemas como a religião, a política e a economia.

Segundo Luhmann, "a autonomização do direito em relação a fundamentações religiosas, morais e científicas, assim como sua positivação são uma conquista moderna. Não permitem voltar atrás". ${ }^{21}$ Ao invés da busca por unidade, o ponto de partida para se pensar o sistema é um princípio de diferenciação: ele não é meramente uma unidade, mas uma diferença. Trata-se, assim, de um paradoxo: um sistema consegue produzir sua própria unidade, na medida em que realiza uma diferença em relação aos demais sistemas. Essa diferença é obtida na medida em que os sistemas permaneçam como entes fechados. ${ }^{22}$

O sistema do direito, portanto, especificou-se funcionalmente como uma ordem normativa autônoma, dirigida racionalmente, o que rejeita um direito absorvido pela moral, pela religião, pela política etc. Mas como o direito é visto em termos de interesse, constantemente interesses morais, religiosos e políticos pressionam o sistema a fim de serem reconhecidos como jurídicos.

A partir desse pano de fundo do direito subjetivo alicerçado na autonomia individual e no conceito de direito pensado como sistema, os direitos fundamentais emergiram e passaram a ser considerados, ao mesmo tempo, como a base a partir da qual todo o arcabouço jurídico se constrói e como um fim a que toda sociedade que se pretenda justa deve buscar atingir.

No entanto, seria possível que o próprio sistema jurídico moderno, ao produzir direitos em excesso, esteja provocando o surgimento de disfunções que acabam

21 LUHMANN, Niklas. Los derechos fundamentales como instituición: aportación a la sociologia política. México, D.F.: Universidad Iberoamericana, 2010, pp.121-122.

22 LUHMANN, Niklas. Introdução à teoria dos sistemas. Petrópolis: Vozes, 2009, p. 101. 
GUALTIERI, André. O problema da inflação de direitos: causas e riscos. Revista Eletrônica Direito e Política, Programa de Pós-Graduação Stricto Sensu em Ciência Jurídica da UNIVALI, Itajaí, v.16, n.1, $1^{\circ}$ quadrimestre de 2021. Disponível em: www.univali.br/direitoepolitica - ISSN 1980-7791

por comprometê-lo? A inflação de direitos estaria impulsionando um desenvolvimento irracional do direito que acabaria prejudicando toda a sociedade?

Embora seja possível apontar já na origem do moderno discurso dos direitos algumas razões para a deflagração do processo inflacionário, há também mudanças doutrinárias que contribuíram decisivamente para isso. Com efeito, a inflação dos direitos só se tornou de fato um problema quando se adotou um novo modelo global dos direitos fundamentais em substituição a uma narrativa tradicional.

Essa narrativa tradicional sobre os direitos fundamentais se apoiava em quatro pontos: (1) eles tinham um âmbito limitado, pois protegiam apenas certos interesses especialmente importantes dos indivíduos; (2) eles impunham obrigações apenas ou principalmente negativas para o Estado; (3) eles operavam apenas entre um cidadão e seu governo, não entre cidadãos particulares; e (4) eles possuíam uma força normativa especial, o que significava que eles podiam ser preteridos, se for o caso, apenas em circunstâncias muito excepcionais. ${ }^{23}$

O modelo global dos direitos fundamentais da atualidade há muito já descartou esses quatro pontos. As doutrinas e desenvolvimentos do direito constitucional que levaram à sua erosão são a inflação de direitos, as obrigações positivas e os direitos socioeconômicos, a eficácia horizontal dos direitos fundamentais e o princípio da proporcionalidade. Este é o núcleo do modelo global dos direitos fundamentais na atualidade. ${ }^{24}$

Na Europa, a inflação de direitos tem sido entendida como uma situação na qual os direitos fundamentais deixam de proteger apenas aqueles interesses considerados de especial importância, passando a adquirir, portanto, um caráter trivial. ${ }^{25}$ Trata-se de um processo de trivialização dos direitos. Uma coisa se torna trivial quando perdemos a "capacidade de diferenciá-la e avaliá-la, quando ela se

\footnotetext{
${ }^{23}$ MÖLLER, Kai. The global model of constitutional rights. Oxford: Oxford University Press, 2012, p. 2.

${ }^{24}$ MÖLLER, Kai. The global model of constitutional rights. p. 4.

25 MÖLLER, Kai. The global model of constitutional rights. p. 19.
} 
GUALTIERI, André. O problema da inflação de direitos: causas e riscos. Revista Eletrônica Direito e Política, Programa de Pós-Graduação Stricto Sensu em Ciência Jurídica da UNIVALI, Itajaí, v.16, n.1, 10 quadrimestre de 2021. Disponível em: www.univali.br/direitoepolitica - ISSN 1980-7791

torna tão comum que passamos a conviver com ela sem nos apercebermos disso, gerando, portanto, alta indiferença em face das diferenças". ${ }^{26}$

Joseph Raz (2010) lista um número - sempre crescente - de direitos que passaram a ser reivindicados como direitos fundamentais: o direito ao prazer sexual; o direito à informação sexual com base em pesquisa científica; o direito à educação sexual abrangente; o direito de todas as pessoas a um meio ambiente seguro, saudável e ecologicamente correto; o direito das gerações futuras de ter suas necessidades atendidas de forma equitativa; o direito de todos à proteção e preservação do ar, solo, água, gelo marinho, flora e fauna, e aos processos e áreas essenciais necessários para manter a diversidade biológica. Alguns acadêmicos defendem um direito humano à globalização; outros defendem a existência de direitos como o de não ser exposto de forma excessiva e desnecessária ao trabalho pesado, degradante, sujo e chato; o de se identificar com o próprio produto de trabalho, individual ou coletivamente; o de haver transparência social; o direito à coexistência com a natureza; o direito contra a pobreza e o direito a ser amado. ${ }^{27}$

No Brasil, o fenômeno da inflação de direitos foi apontado, ainda que em relação ao texto da constituição de 1988 e não à atuação dos Tribunais na interpretação constitucional, por Manoel Gonçalves Ferreira Filho:

(...) a Carta de 1988 explicitou numerosíssimos direitos 'fundamentais', muitíssimos mais do que as anteriores e mesmo que as estrangeiras. Basta lembrar que, se a constituição alemã enuncia cerca de vinte e poucos direitos fundamentais, o art. 153 da Emenda n. 1/69 arrolava cerca de trinta e cinco direitos e garantias e o art. $5^{\circ}$ da atual enumera pelo menos setenta e seis, afora os nove ou dez do art. 60, afora os que se depreendem do art. 150 relativos à matéria tributária, afora o direito ao meio ambiente (art. 225), o direito à comunicação social (art. 220), portanto, cerca de uma centena, se se considerar que vários dos itens do art. $5^{\circ}$ consagram mais de um direito ou garantia. Quer dizer, três vezes mais do que o texto brasileiro anterior, cinco vezes mais do que a Declaração alemã. Há, portanto, na Carta vigente uma 'inflação' de direitos fundamentais. ${ }^{28}$

\footnotetext{
${ }^{26}$ FERRAZ JR., Tercio Sampaio. Introdução ao estudo do direito: técnica, decisão, dominação, p. 171.

27 RAZ, Joseph. Human rights without foundations. In: BESSON, Samantha; TASIOULAS, John. The philosophy of international law. Oxford: Oxford University Press, 2010. p. 321-348, p. 322.

${ }^{28}$ FERREIRA FILHO, Manoel Gonçalves. Aspectos do direito constitucional contemporâneo. São Paulo: Saraiva, 2003, p. 284.
} 
GUALTIERI, André. O problema da inflação de direitos: causas e riscos. Revista Eletrônica Direito e Política, Programa de Pós-Graduação Stricto Sensu em Ciência Jurídica da UNIVALI, Itajaí, v.16, n.1, $1^{\circ}$ quadrimestre de 2021. Disponível em: www.univali.br/direitoepolitica - ISSN 1980-7791

Embora o problema tenha sido apontado, a doutrina brasileira não avançou em sua discussão, a fim de que se pudesse compreender mais profundamente esse processo inflacionário. É compreensível que essa discussão não tenha avançado no Brasil. Num país com um contingente tão grande de pessoas vivendo abaixo da linha da pobreza, é evidente a existência de um problema social grave que demanda solução, que, na teoria jurídica, tem sido vista em termos da concretização de direitos fundamentais previstos na Constituição de 1988. Daí porque a falta de interesse pelo tema da inflação de direitos, que parece, à primeira vista, irrelevante dada a nossa conjuntura social. A discussão ficaria restrita a países desenvolvidos, em que a população goza de um alto nível de vida.

Mas este raciocínio é falho, na medida em que é possível afirmar que a inflação acaba prejudicando o propósito essencial dos direitos fundamentais, prejudicando, assim, aqueles que mais necessitam deles. Se tudo pode se tornar um direito, a própria noção de direito se torna vazia e de difícil operacionalidade. Se tudo pode ser direito, nada é direito.

Assim, a inflação de direitos é um problema, inclusive do ponto de vista do direito brasileiro. Ela acaba minando a legitimidade do sistema e fazendo com que os direitos fundamentais sejam considerados algo de menor importância, algo que não tem um impacto no mundo real, possuindo um caráter apenas ideal. Como afirma Luhmann, a inflação de direitos dificulta a identificação do que é de fato essencial - a proteção da dignidade da pessoa humana. ${ }^{29}$

\section{A INFLAÇÃO DE DIREITOS E OS TRIBUNAIS}

Como afirmamos acima, a inflação de direitos no contexto europeu tem significado uma tendência crescente de considerar interesses triviais como direitos. A Corte Europeia de Direitos Humanos frequentemente tem agido assim, em virtude de uma interpretação que atribui um sentido amplo ao direito à vida privada,

29 LUHMANN, Niklas. El Derecho de la Sociedad. versão 5.0, de 13/01/2003; - formatação eletrônica - João Protásio Farias Domingues de Vargas e Marjorie Corrêa Marona, 2003, p. 422. 
GUALTIERI, André. O problema da inflação de direitos: causas e riscos. Revista Eletrônica Direito e Política, Programa de Pós-Graduação Stricto Sensu em Ciência Jurídica da UNIVALI, Itajaí, v.16, n.1, 10 quadrimestre de 2021. Disponível em: www.univali.br/direitoepolitica - ISSN 1980-7791

garantido pela Convenção Europeia dos Direitos Humanos, em seu art. $8^{\circ}$. In verbis:

1. Qualquer pessoa tem direito ao respeito da sua vida privada e familiar, do seu domicílio e da sua correspondência. 2. Não pode haver ingerência da autoridade pública no exercício deste direito senão quando esta ingerência estiver prevista na lei e constituir uma providência que, numa sociedade democrática, seja necessária para a segurança nacional, para a segurança pública, para o bemestar económico do país, a defesa da ordem e a prevenção das infrações penais, a proteção da saúde ou da moral, ou a proteção dos direitos e das liberdades de terceiros. ${ }^{30}$

No caso Hatton, de 2003, que tratou da permissão de voos noturnos no aeroporto de Heathrow, cuja poluição sonora perturbava o sono de alguns dos residentes na área, o Tribunal extraiu do artigo $8^{\circ}$ o direito de não ser direta e gravemente afetado por ruído ou outra poluição. Esse entendimento amplo a respeito do sentido do direito à vida privada é resumido no caso $S$. and Marper $v$. the United Kingdom, no qual a Corte Europeia afirmou que:

O conceito de "vida privada" é um termo amplo não suscetível de definição exaustiva. Ele abrange a integridade física e psicológica de uma pessoa. Portanto, pode incluir vários aspectos da identidade física e social da pessoa. Elementos como, por exemplo, identificação de gênero, nome e orientação sexual e vida sexual estão dentro da esfera pessoal protegida pelo art. $8^{\circ}$. Além do nome da pessoa, sua vida privada e familiar pode incluir outros meios de identificação pessoal e de ligação a uma família. Informações sobre a saúde da pessoa é um elemento importante da vida privada. O Tribunal também considera que a identidade étnica de um indivíduo deve ser considerada como outro elemento desse tipo. Além disso, o Artigo $8^{\circ}$ protege o direito ao desenvolvimento pessoal e o direito de estabelecer e desenvolver relacionamentos com outros seres humanos e o mundo exterior. O conceito de vida privada também inclui elementos relacionados ao direito de uma pessoa à sua imagem. ${ }^{31}$

Também foram considerados como parte do amplo conceito de direito à vida privada, o armazenamento de impressões digitais e amostras de DNA pelo estado, a publicação de fotografias de uma pessoa em sua vida cotidiana por uma revista,

30 EUROPA. [Convenção (1950)]. Convenção europeia dos direitos do homem. Disponível em: https://www.echr.coe.int/Documents/Convention POR.pdf. Acesso em: 14 abr. 2020.

31 Corte Europeia de Direitos Humanos. Case of S. and Marper v. the United Kingdom. Applications nos. 30562/04 and 30566/04, 4, de dezembro de 2008, p. 20. Disponível em: https://hudoc.echr.coe.int/app/conversion/docx/pdf?library $=$ ECHR\&id $=001$ -

90051\&filename $=$ CASE\%20OF\%20S.\%20AND\%20MARPER\%20V.\%20THE\%20UNITED\%20KINGDO M.pdf. Acesso em: 28 abr. 2020. 
GUALTIERI, André. O problema da inflação de direitos: causas e riscos. Revista Eletrônica Direito e Política, Programa de Pós-Graduação Stricto Sensu em Ciência Jurídica da UNIVALI, Itajaí, v.16, n.1, 10 quadrimestre de 2021. Disponível em: www.univali.br/direitoepolitica - ISSN 1980-7791

a participação em orgias sadomasoquistas envolvendo violência considerável e o acesso a informações relacionadas ao nascimento e origem de alguém. ${ }^{32}$

Embora a Corte não tenha definido o que é a vida privada, ela considera que ainda é necessário que o interesse a ser examinado possa ser enquadrado como parte desse direito, pois o Tribunal não aceita todo e qualquer interesse como abrangido pelo âmbito de proteção do artigo 8.0, estabelecendo, portanto, um limiar que precisa ser cruzado para que um interesse se torne um direito. ${ }^{33}$

Já o posicionamento da Corte Constitucional Alemã prescinde de qualquer limite a ser utilizado para distinguir um mero interesse de um direito fundamental. Desde 1957, a Corte entende que o art. 20, I, da Constituição Alemã, que protege o direito de todos de livremente desenvolver sua personalidade, deve ser interpretado como um direito à liberdade de agir. Essa interpretação do art. 20, I, foi reafirmada várias vezes, levando o Tribunal a reconhecer direitos como o de alimentar pombos em um parque e o de passear nos bosques. ${ }^{34}$

Assim, como afirma Branco, o direito à vida privada a que se referem os julgados europeus, baseado na ideia de autonomia individual, deve ser entendido como um direito ao livre desenvolvimento da personalidade. ${ }^{35}$

Com isso fica fácil perceber como esse tipo de abordagem produz uma inflação de direitos: quanto mais se busca assegurar o desenvolvimento da personalidade de cada indivíduo, mais se necessita de direitos que tornem isso possível, estabelecendo obrigações negativas ou positivas.

O princípio da proporcionalidade desempenha um papel fundamental nesse processo de inflacionamento dos direitos. Segundo Möller, é amplamente aceito que a análise da proporcionalidade é compatível com a inflação de direitos: por exemplo, é perfeitamente possível aceitar o direito de alimentar pássaros, e aplicar a análise da proporcionalidade para determinar se uma interferência nesse direito

\footnotetext{
32 MÖLLER, Kai. The global model of constitutional rights. p. 3 .

33 MÖLLER, Kai. The global model of constitutional rights. p. 4.

34 MÖLLER, Kai. The global model of constitutional rights. p.4.

35 BRANCO, Paulo Gustavo Gonet; MENDES, Gilmar Ferreira. Curso de direito constitucional. 11 ed. São Paulo: Saraiva, 2016, p. 281.
} 
GUALTIERI, André. O problema da inflação de direitos: causas e riscos. Revista Eletrônica Direito e Política, Programa de Pós-Graduação Stricto Sensu em Ciência Jurídica da UNIVALI, Itajaí, v.16, n.1, 10 quadrimestre de 2021. Disponível em: www.univali.br/direitoepolitica - ISSN 1980-7791

é justificável. Mas mais importante que isso, é entender que a proporcionalidade não é apenas compatível com a inflação de direitos, e sim necessária para que ela ocorra. Desse modo, proporcionalidade e inflação de direitos seriam dois lados da mesma moeda, pois a existência de uma implica a existência da outra. ${ }^{36}$

Essa concepção de direito defendida por Möller não se baseia na ideia de que certos interesses especialmente importantes devem ser selecionados para receber uma maior proteção jurídica. Ao invés disso, o que ela afirma é que cada uma das medidas estatais que afetam a capacidade de uma pessoa viver sua vida à sua própria maneira deve levar em conta os interesses decorrentes da autonomia individual. Isso faz com que todos os interesses resultantes da autonomia individual devam ser qualificados como direitos, ao mesmo tempo em que não há direitos absolutos. ${ }^{37}$

Inflação de direitos e proporcionalidade, portanto, têm uma relação de dependência mútua e juntas desempenham uma função crucial para uma concepção de direitos fundamentada na ideia de que cada pessoa tem autonomia para viver a vida de acordo com sua vontade. Segundo Möller,

\begin{abstract}
A inflação de direitos é necessária porque mostrar a atitude certa em relação a uma pessoa requer tomar todos os seus projetos com seriedade, incluindo aqueles de importância trivial e até imorais ou maus. A proporcionalidade é necessária porque, adequadamente compreendida, ela avalia exatamente a questão de saber se os interesses individuais de alguém foram adequadamente levados em consideração pela política que interfere em sua autonomia. ${ }^{38}$
\end{abstract}

Assim, a tendência dos Tribunais europeus de incluir uma variedade de interesses no âmbito dos direitos humanos é consequência da própria lógica da proporcionalidade.

A Constituição brasileira de 1988 estabelece a vida privada como um direito fundamental, no inciso $X$, do art. 50. Mas enquanto na Europa esse direito costuma ser tratado de modo abrangente, no Brasil ele é entendido num sentido mais

\footnotetext{
36 MÖLLER, Kai. Proportionality and rights inflation. In: HUSCROFT, Grant; MILLER, Bradley W.; WEBBER, Grégoire. Proportionality and the Rule of Law: rights, justification, reasoning. Cambridge: Cambridge University Press, 2014. p. 155-172, p. 159.

37 MÖLLER, Kai. Proportionality and rights inflation. p. 161.

38 MÖLLER, Kai. Proportionality and rights inflation. p. 167.
} 
GUALTIERI, André. O problema da inflação de direitos: causas e riscos. Revista Eletrônica Direito e Política, Programa de Pós-Graduação Stricto Sensu em Ciência Jurídica da UNIVALI, Itajaí, v.16, n.1, $1^{\circ}$ quadrimestre de 2021. Disponível em: www.univali.br/direitoepolitica - ISSN 1980-7791

restrito, como privacidade, isto é, "o direito de não ser foco da observação por terceiros, de não ter os seus assuntos, informações pessoais e características particulares expostas a terceiros ou ao público em geral". 39

No Brasil, afirma Branco, essa visão mais abrangente não parece necessária, pois a proteção do indivíduo contra interferências indevidas do Estado pode ser obtida por meio dos princípios da proporcionalidade, da liberdade e da dignidade da pessoa humana. Este último, garante a proteção de uma margem de autonomia individual tão ampla quanto possível, dada sua convivência com outros valores constitucionais. ${ }^{40}$

A observação não parece explicar adequadamente a razão pela qual no Brasil não se adotou essa concepção mais abrangente de proteção à vida privada, pois os outros princípios mencionados pelo autor também são reconhecidos pelas Cortes europeias. Mas independentemente disso, o fato é que nosso STF não adota essa dimensão mais abrangente do direito à vida privada e tampouco tem atribuído qualidade de direitos fundamentais a interesses meramente triviais.

Assim, parece que no Brasil a inflação de direitos não deve ter o mesmo significado que se atribui ao termo no contexto europeu. O que ocorre em nosso país parece ser muito mais o caso de uma constante criação de novos direitos, que pode ser vista por alguns como excessiva, do que a prática de atribuir a interesses triviais o status de direitos fundamentais. A inflação de direitos no Brasil, portanto, deve ser compreendida simplesmente como um processo constante de criação de direitos, que se dá tanto pela atividade legislativa quanto por obra do poder judiciário e que, quando acontece no âmbito deste poder, ocorre tanto em razão da chamada judicialização quanto do princípio da proporcionalidade.

A judicialização, que não é um fenômeno apenas brasileiro, significa que algumas "questões de larga repercussão política ou social estão sendo decididas por órgãos

39 BRANCO, Paulo Gustavo Gonet; MENDES, Gilmar Ferreira. Curso de direito constitucional. p. 283.

40 BRANCO, Paulo Gustavo Gonet; MENDES, Gilmar Ferreira. Curso de direito constitucional. p. 283. 
GUALTIERI, André. O problema da inflação de direitos: causas e riscos. Revista Eletrônica Direito e Política, Programa de Pós-Graduação Stricto Sensu em Ciência Jurídica da UNIVALI, Itajaí, v.16, n.1, $1^{\circ}$ quadrimestre de 2021. Disponível em: www.univali.br/direitoepolitica - ISSN 1980-7791

do Poder Judiciário, e não pelas instâncias políticas tradicionais: o Congresso Nacional e o Poder Executivo". ${ }^{41}$

As causas especificamente brasileiras da judicialização são as seguintes:

A Constituição de 1988 , ponto culminante no processo de redemocratização do país, transformou o Judiciário "em um verdadeiro poder político, capaz de fazer valer a Constituição e as leis, inclusive em confronto com os outros Poderes". ${ }^{42}$

A constituição abrangente, "que trouxe para a Constituição inúmeras matérias que antes eram deixadas para o processo político majoritário e para a legislação ordinária". ${ }^{43}$ As constituições portuguesa, espanhola e brasileira são todas cartas que se enquadram nessa classificação.

O sistema brasileiro de controle de constitucionalidade, que pode admitir tanto o controle difuso quanto o concentrado, é um dos mais abrangentes do mundo, tornando possível que "quase qualquer questão política ou moralmente relevante pode ser alçada ao STF". ${ }^{44}$

Soma-se à judicialização, que é uma questão de fato, o chamado ativismo judicial que consiste numa atitude, numa escolha do magistrado de adotar uma postura mais proativa ao interpretar a Constituição, resultando na expansão do seu sentido e alcance. Normalmente, afirma Barroso, o ativismo ocorre como uma espécie de reação a uma postura omissiva do Poder Legislativo, que leva a "um certo descolamento entre a classe política e a sociedade civil, impedindo que as demandas sociais sejam atendidas de maneira efetiva". ${ }^{45}$

Assim, o ativismo se manifesta por meio de alguns tipos de conduta, que incluem:

a) a aplicação direta da Constituição a situações não expressamente contempladas em seu texto e independentemente de manifestação do legislador ordinário; b) a declaração de inconstitucionalidade de

41 BARROSO, Luís Roberto. Judicialização, ativismo judicial e legitimidade democrática. (Syn)Thesis, Rio de Janeiro, vol. 5, $\mathrm{n}^{\circ}$ 1, 2012. Disponível em: https://www.epublicacoes.uerj.br/index.php/synthesis/article/view/7433/5388. Acesso em: 28 abr. 2020. p. 2332 , p. 24.

42 BARROSO, Luís Roberto. Judicialização, ativismo judicial e legitimidade democrática. p. 24.

43 BARROSO, Luís Roberto. Judicialização, ativismo judicial e legitimidade democrática. p. 24.

44 BARROSO, Luís Roberto. Judicialização, ativismo judicial e legitimidade democrática. p. 25.

45 BARROSO, Luís Roberto. Judicialização, ativismo judicial e legitimidade democrática. p. 25. 
GUALTIERI, André. O problema da inflação de direitos: causas e riscos. Revista Eletrônica Direito e Política, Programa de Pós-Graduação Stricto Sensu em Ciência Jurídica da UNIVALI, Itajaí, v.16, n.1, 10 quadrimestre de 2021. Disponível em: www.univali.br/direitoepolitica - ISSN 1980-7791

atos normativos emanados do legislador, com base em critérios menos rígidos que os de patente e ostensiva violação da Constituição; c) a imposição de condutas ou de abstenções ao Poder Público, notadamente em matéria de políticas públicas. ${ }^{46}$

O princípio da proporcionalidade, por sua vez, também tem sido um instrumento utilizado pelo STF para a criação de novos direitos. Não é exatamente inflação no sentido dado por Möller, mas é um processo inflacionário no sentido de que cada vez mais novos direitos têm nascido em virtude da atuação da Corte. A utilização da proporcionalidade pelo Tribunal para esse fim, ainda que tímida se comparada aos Tribunais europeus, tem sido um dos elementos que tem causado no Brasil uma inflação de direitos. Abaixo, apresento alguns exemplos disso na jurisprudência do STF.

Na ADPF 54, foi garantido o direito da mulher ao aborto de feto anencefálico:

Os perigos para a saúde física da mulher, como visto, são elevadíssimos em uma gravidez de feto acometido pela anencefalia, razão pela qual, se essa for a alternativa eleita pela mulher, deve-se conferir a possibilidade de interrupção da gestação à luz do princípio da proporcionalidade, que também se aplica ao Direito Penal. ${ }^{47}$

Na ADI 4.424, entendeu-se que a ação penal relativa à lesão corporal resultante de violência doméstica contra a mulher é pública incondicionada:

Não se coaduna com a razoabilidade, não se coaduna com a proporcionalidade, deixar a atuação estatal a critério da vítima, a critério da mulher, cuja espontânea manifestação de vontade é cerceada por diversos fatores da convivência no lar, inclusive a violência a provocar o receio, o temor, o medo de represálias. ${ }^{48}$

No HC 124.306 argumentou-se que a criminalização do aborto viola o princípio da proporcionalidade:

(...) é preciso conferir interpretação conforme a Constituição aos próprios arts. 124 a 126 do Código Penal - que tipificam o crime de

46 BARROSO, Luís Roberto. Judicialização, ativismo judicial e legitimidade democrática. p. 26.

47 BRASIL. Supremo Tribunal Federal. Ação de descumprimento de preceito fundamental 54. Relator: Min. Marco Aurélio, 12 de abril de 2012. Disponível em: http://redir.stf.jus.br/paginadorpub/paginador.jsp?docTP=TP\&docID=3707334. Acesso em: 25 abr. 2020.

48 BRASIL. Supremo Tribunal Federal. Ação Direta de Inconstitucionalidade 4.424. Relator: Min. Marco Aurélio, 9 de fevereiro de 2012. Disponível em: http://redir.stf.jus.br/paginadorpub/paginador.jsp?docTP=TP\&docID=6393143. Acesso em: 25 abr. 2020. 
GUALTIERI, André. O problema da inflação de direitos: causas e riscos. Revista Eletrônica Direito e Política, Programa de Pós-Graduação Stricto Sensu em Ciência Jurídica da UNIVALI, Itajaí, v.16, n.1, 10 quadrimestre de 2021. Disponível em: www.univali.br/direitoepolitica - ISSN 1980-7791

aborto - para excluir do seu âmbito de incidência a interrupção voluntária da gestação efetivada no primeiro trimestre. A criminalização, nessa hipótese, viola diversos direitos fundamentais da mulher, bem como o princípio da proporcionalidade. ${ }^{49}$

Decisões inovadoras como essas muitas são muitas vezes objeto de críticas. Autores como Huscroft, por exemplo, não veem com bons olhos posicionamentos desse tipo, ao afirmar a importância de nos preocuparmos com significado dos direitos que temos, o que só pode ser encontrado na decisão fundamental de uma comunidade política de promulgar uma declaração de direitos. ${ }^{50}$ É nessa declaração, a Constituição de 1988 no nosso caso, que encontramos a escolha da comunidade política em relação a quais direitos devem receber uma proteção especial.

Assim, os direitos fundamentais são finitos por natureza, pois são fruto de uma escolha em relação a alguns interesses - não todos - que obtêm uma proteção especial por terem sido alçados a estatura de um direito fundamental. Como esses direitos refletem um acordo constitucional sobre questões de direitos, esse acordo deve ser respeitado antes que qualquer análise de proporcionalidade possa ocorrer. ${ }^{51}$

Esses pressupostos fazem com que Huscroft se coloque contra a tese de Möller de que a inflação e a proporcionalidade seriam elementos necessários para um direito que se baseia na autonomia do indivíduo. Para Huscroft, essa aliança não pode ser aceita por duas razões fundamentais.

Em primeiro lugar, ela torna o processo de interpretação dos direitos irrelevante, na medida em que o que deve resultar dela é sempre a maior extensão possível de um direito. Vejamos:

Atualmente, a interpretação é um exercício difícil e muitas vezes controverso, e é fácil entender por que os tribunais podem preferir

\footnotetext{
49 BRASIL. Supremo Tribunal Federal. Habeas Corpus 124.306. Relator: Min. Roberto Barroso, 9 de agosto de 2016. Disponível em: http://redir.stf.jus.br/paginadorpub/paginador.jsp?docTP $=T P \& d o c I D=12580345$. Acesso em: 25 abr. 2020.

50 HUSCROFT, Grant. Proportionality and the relevance of interpretation. In: HUSCROFT, Grant; MILLER, Bradley W.; WEBBER, Grégoire. Proportionality and the Rule of Law: rights, justification, reasoning. Cambridge: Cambridge University Press, 2014. p. 186-202.

51 HUSCROFT, Grant. Proportionality and the relevance of interpretation. p. 188.
} 
GUALTIERI, André. O problema da inflação de direitos: causas e riscos. Revista Eletrônica Direito e Política, Programa de Pós-Graduação Stricto Sensu em Ciência Jurídica da UNIVALI, Itajaí, v.16, n.1, $1^{\circ}$ quadrimestre de 2021. Disponível em: www.univali.br/direitoepolitica - ISSN 1980-7791

resolver conflitos entre direitos usando a análise da proporcionalidade: ela oferece uma estrutura analítica familiar que se propõe a entregar resultados objetivos. Inspirados pelo direito alemão, no entanto, os principais defensores da proporcionalidade vão além, defendendo que a interpretação deve, em essência, ser abandonada. A conveniência normativa de justificação é tudo o que importa, eles argumentam, e os direitos devem ser interpretados o mais amplamente possível para justificar a ação estatal estabelecida através da análise de proporcionalidade - na maior extensão possível. ${ }^{52}$

Em segundo lugar, ao expandir o âmbito dos direitos e, com ela, a própria jurisdição, a concepção de proporcionalidade proposta por Möller efetua mudanças radicais na ordem constitucional e, por isso, deve ser rejeitada, ainda que haja circunstâncias em que uma ampliação da ação estatal seja desejável.

Huscroft dá ao exame sobre o significado dos direitos uma importância que a tese da necessidade da inflação desconhece. Para ele, determinar o significado de um direito deve ser uma condição prévia à decisão de se realizar uma análise de proporcionalidade. Vejamos:

A fim de respeitar a decisão da comunidade ao adotar uma Constituição, os Tribunais na aplicação da proporcionalidade devem respeitar não apenas a prioridade moral dos direitos, mas também a essência dos direitos específicos que a comunidade se comprometeu a proteger. Por isso, argumentarei que a decisão de adotar uma declaração de direitos é uma decisão de conceder status legal a direitos específicos, ao invés de direitos em geral. Se um direito específico está protegido por uma declaração de direitos, e qual é a sua proteção, são questões anteriores à autoridade dos tribunais de realizarem uma análise de proporcionalidade. ${ }^{53}$

A concepção de Huscroft não é conciliável com a de Möller, pois parte da ideia de que como a Constituição traz uma lista de direitos específicos, isso tornaria impossível uma interpretação que tratasse esses direitos de forma abrangente, como resultado da autonomia individual. Além disso, Huscrof critica os defensores da proporcionalidade por aceitarem um modelo no qual a validade de todas as promessas democraticamente estabelecidas no ordenamento jurídico passa a depender da aprovação judicial, que carece da legitimidade democrática que possui o legislativo, pois "as Constituições refletem escolhas e compromissos de

\footnotetext{
52 HUSCROFT, Grant. Proportionality and the relevance of interpretation. p.187.

53 HUSCROFT, Grant. Proportionality and the relevance of interpretation. p. 188.
} 
GUALTIERI, André. O problema da inflação de direitos: causas e riscos. Revista Eletrônica Direito e Política, Programa de Pós-Graduação Stricto Sensu em Ciência Jurídica da UNIVALI, Itajaí, v.16, n.1, $1^{\circ}$ quadrimestre de 2021. Disponível em: www.univali.br/direitoepolitica - ISSN 1980-7791

uma comunidade política moralmente significativos, e essas escolhas devem exigir o respeito do judiciário". 54

\section{OS RISCOS DA INFLAÇÃO DE DIREITOS}

A atuação do judiciário brasileiro, em especial do Supremo Tribunal Federal, está mais próxima do modelo descrito por Möller do que do modelo de Huscroft. Com efeito, em nosso direito isso decorre da própria Constituição de 1988, que adotou um "sistema aberto de direitos fundamentais". ${ }^{55} \mathrm{O} \S 20$, do art. 50 , da Constituição prevê a não taxatividade do rol de direitos fundamentais: "os direitos e garantias expressos nesta Constituição não excluem outros decorrentes do regime e dos princípios por ela adotados, ou dos tratados internacionais em que a República Federativa do Brasil seja parte". ${ }^{56}$

Isso, naturalmente, não elimina do contexto brasileiro os riscos de uma inflação de direitos e a consequente necessidade debatê-los. Como o direito moderno está fundado a partir da autonomia individual, isso acaba gerando um processo inflacionário, seja no sentido de atribuir a interesses triviais a qualidade de direitos, seja no sentido de gerar um processo de incessante proliferação de direitos e de judicialização de vidas.

Diante desse quadro, Raz aponta a necessidade de que a doutrina articule padrões pelos quais a prática dos direitos humanos possa ser avaliada. Esses padrões devem indicar quais direitos realmente possuímos e ao fazê-lo, elucidará qual é o significado de um direito ser um direito humano. ${ }^{57}$

\footnotetext{
54 HUSCROFT, Grant. Proportionality and the relevance of interpretation. p. 202.

55 BRANCO, Paulo Gustavo Gonet; MENDES, Gilmar Ferreira. Curso de direito constitucional. p. 168.

56 BRASIL. [Constituição (1988)]. Constituição da República Federativa do Brasil de 1988. Brasília, DF: Presidência da República, [2020]. Disponível em: http://www.planalto.gov.br/ccivil 03/constituicao/constituicao.htm. Acesso em: 14 abr. 2020.

57 RAZ, Joseph. Human rights without foundations. p. 322.
} 
GUALTIERI, André. O problema da inflação de direitos: causas e riscos. Revista Eletrônica Direito e Política, Programa de Pós-Graduação Stricto Sensu em Ciência Jurídica da UNIVALI, Itajaí, v.16, n.1, 10 quadrimestre de 2021. Disponível em: www.univali.br/direitoepolitica - ISSN 1980-7791

No mesmo sentido, "é conveniente encontrar um princípio limitador à uma inflação legislativa e regulamentar, que podemos temer irá produzir um tipo de autoanulação". 58

Curiosamente, a noção de um direito produzido a partir do desejo do ser humano autônomo, parece, com o tempo, levar o sistema, tal qual descrito por Luhmann, a uma contradição interna, pois a expansão sem fim de direitos traz o risco do trasbordamento do sistema, isto é, uma situação na qual o excesso de direitos compromete seu fechamento e sua consequente diferenciação em relação aos demais sistemas, fazendo com que já não seja mais possível separar o direito de outras esferas como a moral e a política.

A inflação de direitos representa, portanto, um problema para a saúde do sistema do direito. Luhmann enfatiza a importância de proteger a diferenciação entre os sistemas. A concepção liberal de direito, ao propor uma Constituição que estabelecia direitos fundamentais, buscava justamente resolver o problema da conservação da ordem social funcionalmente diferenciada e da proteção do campo de ação próprio do direito. Isso evitaria a desdiferenciação, isto é, a situação na qual sistemas anteriormente autônomos deixam de sê-lo, tornando-se um só, o que acontece, por exemplo, quando o sistema político invade o sistema jurídico, acabando com sua autonomia. ${ }^{59}$

No entanto, o desenvolvimento do direito do século XIX para cá nos mostrou o contrário. A tendência inflacionária presente no cerne dos direitos fundamentais acabou contribuindo para que a autonomia do direito passasse a ser constantemente ameaçada por outras esferas, como a política e a moral. O direito baseado no indivíduo autônomo e seu infindável desejo produz o curioso efeito de que a diferenciação entre direito e política se torne cada vez mais tênue, pois, na medida em que o rol de direitos se alarga, o direito se torna progressivamente refém de interesses políticos e de moralidades específicas. Além disso, como nas sociedades democráticas há uma tendência de se politizar os mais diversos

\footnotetext{
58 BARRETO, Vicente de Paulo. O fetiche dos direitos humanos. Porto Alegre: Livraria do Advogado Editora, 2010, p. 32.

59 LUHMANN, Niklas. Los derechos fundamentales como instituición: aportación a la sociologia política. México, D.F.: Universidad Iberoamericana, 2010, p. 22.
} 
GUALTIERI, André. O problema da inflação de direitos: causas e riscos. Revista Eletrônica Direito e Política, Programa de Pós-Graduação Stricto Sensu em Ciência Jurídica da UNIVALI, Itajaí, v.16, n.1, 10 quadrimestre de 2021. Disponível em: www.univali.br/direitoepolitica - ISSN 1980-7791

aspectos da vida, os próprios direitos fundamentais acabam fazendo parte dessa politização.

Outro problema apontado por Luhmann é o perigo de que o sistema se torne inviável por não conseguir se adaptar a tantos novos elementos que são constantemente nele introduzidos. A inflação, portanto, representaria um perigo para a sobrevivência do próprio sistema do direito. Assim, questões referentes ao limite da capacidade de adaptação do sistema e de quantas transformações poderíamos introduzir nele sem colocá-lo em perigo passam a ser relevantes. Esses problemas afetam, por exemplo, a discussão a respeito da longevidade do modelo de Estado de bem-estar social, também adotado pela Constituição brasileira de 1988:

As derivações para os problemas ecológicos e para o Estado de bemestar social saltam aos olhos: até onde é possível o aumento progressivo das compensações do referido Estado, as quais, por outro lado exigem incremento progressivo de política impositiva? (...) Em qual relação os cargos públicos devem aumentar?60

O risco, portanto, é de que a tendência dos direitos fundamentais de serem criados ilimitadamente acabe representando uma ameaça à estabilidade do direito, ao funcionarem como uma espécie de buraco negro que suga tudo o que se encontra ao seu redor. A situação é paradoxal, pois há uma "inclinação do sistema a se deixar levar por uma força que o transforma, mas que, ao perder de vista o sentido benéfico, converte-se em ameaça. Ameaça esta que deve ser considerada, quando se quer controlar a evolução do sistema". ${ }^{61}$

Por fim, a inflação poderia comprometer o valor máximo que justifica a existência dos próprios direitos fundamentais, isto é, o princípio da dignidade da pessoa humana, que é o que realmente merece ser incondicionalmente protegido. Isso ocorreria na medida em que o excesso de direitos tornaria impossível a real concretização de todos eles. Assim, a inflação levaria o valor simbólico da

\footnotetext{
60 LUHMANN, Niklas. Introdução à teoria dos sistemas. Petrópolis: Vozes, 2009, pp. 70-71.
}

61 LUHMANN, Niklas. Introdução à teoria dos sistemas. Petrópolis: Vozes, 2009, p. 72. 
GUALTIERI, André. O problema da inflação de direitos: causas e riscos. Revista Eletrônica Direito e Política, Programa de Pós-Graduação Stricto Sensu em Ciência Jurídica da UNIVALI, Itajaí, v.16, n.1, 10 quadrimestre de 2021. Disponível em: www.univali.br/direitoepolitica - ISSN 1980-7791

dignidade humana à ruína, comprometendo, sua proteção, pois em todo lugar se torna normal que os direitos fundamentais não sejam observados. ${ }^{62}$

Trata-se de um problema relativo à delimitação do sentido desses direitos. Quando temos dificuldades para delimitar o sentido do que se comunica, surge um problema que afeta a função integradora do processo de comunicação das sociedades democráticas modernas, que, tem justamente nos direitos fundamentais seu elemento integrador. Sem a comunicação, a integração social é impensável. É de importância secundária se esta comunicação ocorre ou não intencionalmente, se pretende dar-se a conhecer um sentido ou se este somente se pode deduzir do comportamento, e se a intenção de o dar a conhecer se expressa se coexpressa ou se cala. A função integradora do processo de comunicação consiste em que o sentido que se dá a conhecer remete direta ou indiretamente a sistemas de ação. ${ }^{63}$

Em virtude da autonomia individual, que gera a busca pela satisfação do ilimitado desejo humano, tudo potencialmente pode se transformar em direito, fazendo com que seu sentido fique fluido, difícil de ser delimitado. Isso prejudica a comunicação com base em direitos, prejudicando, portanto, a integração social da sociedade moderna e o próprio Direito enquanto sistema.

\section{A NECESSIDADE DE LIMITAÇÃO DO PROCESSO INFLACIONÁRIO}

Para que a doutrina possa cumprir a função de limitar os direitos fundamentais, limitando, assim seu processo inflacionário, ela deve se preocupar com a consistência lógica de seus argumentos, pois, caso contrário, essa delimitação não pode ser adequadamente realizada. É o que Luhmann argumenta ao apontar como insatisfatória a lógica utilizada na fundamentação desses direitos, cujas premissas contém uma antítese, o que permite qualquer resultado como produto da dedução. Afirmar que a dignidade é a essência do homem e que, portanto, o ser humano

62 LUHMANN, Niklas. El Derecho de la Sociedad. versão 5.0, de 13/01/2003; - formatação eletrônica - João Protásio Farias Domingues de Vargas e Marjorie Corrêa Marona, 2003, p. 422.

63 LUHMANN, Niklas. Los derechos fundamentales como instituición: aportación a la sociologia política. p. 130. 
GUALTIERI, André. O problema da inflação de direitos: causas e riscos. Revista Eletrônica Direito e Política, Programa de Pós-Graduação Stricto Sensu em Ciência Jurídica da UNIVALI, Itajaí, v.16, n.1, 10 quadrimestre de 2021. Disponível em: www.univali.br/direitoepolitica - ISSN 1980-7791

tem direito à dignidade são afirmações que se excluem mutuamente, pois "só se pode ter direito ao que se pode perder, e por essência se entende justamente a qualidade que não se pode perder de uma substancia". ${ }^{64}$

Normas como o artigo 19, § 20 da Constituição Alemã - "em nenhum caso, um direito fundamental poderá ser violado em sua essência" - não são suficientes para lidar com o problema, "pois o conceito de essência se dissolveu com o declínio dos pressupostos ontológicos do nosso filosofar, convertendo-se em simples fórmula vazia". ${ }^{65}$ Desse modo, ficamos diante de uma situação em que a insegurança se torna grande, pois, qualquer decisão é possível.

A solução desse problema passa pelo sistema político cumprir adequadamente suas funções, assumindo suas próprias responsabilidades. Há, portanto, a necessidade de decisões políticas: "não se deve escamotear a responsabilidade política remetendo tais decisões aos Tribunais".66 Para Luhmann, devemos "depositar na legislação a parte da carga de explicação e detalhe por parte dos Tribunais". ${ }^{67}$ Isto traria maior segurança à interpretação e à aplicação dos direitos fundamentais.

Uma outra questão está na incapacidade que os argumentos valorativos têm de diminuir a incerteza, pois os valores, na verdade, permitem que se argumente sobre temas complexos da realidade como se fossem questões banais, simples de serem resolvidas. A teoria do valor superestima a liberdade de ação, como se tudo fosse questão de vontade, pois ela

desperta a impressão de que se trata tão somente de que reconheçamos os postulados dos valores e que os sigamos, ou que, de maneira malvada, não os busquemos e persigamos outros valores. ${ }^{68}$

\footnotetext{
64 LUHMANN, Niklas. Los derechos fundamentales como instituición: aportación a la sociologia política. p. 146. ${ }_{65}$ LUHMANN, Niklas. Los derechos fundamentales como instituición: aportación a la sociologia política. p. 146. ${ }_{66}$ LUHMANN, Niklas. Los derechos fundamentales como instituición: aportación a la sociologia política. p. 321. 67 LUHMANN, Niklas. Los derechos fundamentales como instituición: aportación a la sociologia política. p. 324. 68 LUHMANN, Niklas. Los derechos fundamentales como instituición: aportación a la sociologia política. p. 327.
} 
GUALTIERI, André. O problema da inflação de direitos: causas e riscos. Revista Eletrônica Direito e Política, Programa de Pós-Graduação Stricto Sensu em Ciência Jurídica da UNIVALI, Itajaí, v.16, n.1, 10 quadrimestre de 2021. Disponível em: www.univali.br/direitoepolitica - ISSN 1980-7791

Mas além de uma tarefa teórica, a imposição de limites é também uma tarefa jurisdicional. Daí a importância do debate jurídico que se realiza nos Tribunais constitucionais acerca do alcance da proteção dos Direitos Fundamentais. ${ }^{69}$

Neste campo, é preciso, em primeiro lugar, evitar o uso retórico dos princípios jurídicos, isto é, a situação na qual "o caráter jurídico-institucional antes reclamado para os princípios jurídicos é substituído pelo poder argumentativo das partes e do juiz". ${ }^{70}$ É importante notar que "o discurso do Supremo Tribunal Federal não possui uma doutrina mais rígida sobre a noção de princípio jurídico". ${ }^{71}$ Isso acaba fazendo com que os princípios em geral, e a proporcionalidade em especial, fiquem reduzidos a desempenhar uma função eminentemente retórica, sem grande consistência. Em segundo lugar, é preciso também evitar a incoerência nas decisões judiciais que são frequentemente justificadas por esse uso retórico da proporcionalidade. ${ }^{72}$

Diante desse quadro, é pertinente lembrar a observação de Luhmann de que faz falta à versão moderna - idealista - de justiça (como valor) uma compreensão mais realista, como a que encontramos no pensamento aristotélico. ${ }^{73}$ Seria útil, portanto, redescobrir uma noção de justiça comprometida com o caso concreto, ou seja, com aquilo que Aristóteles chamava de equidade: a justiça na concretude.

\section{CONSIDERAÇÕES FINAIS}

Procurei mostrar que o direito moderno, que tem como fundamento a autonomia individual, passa por um processo inflacionário, seja no sentido de atribuir a

69 ZOLET, L., MORAIS, F. Inflação dos direitos fundamentais e os vícios e virtudes do princípio da proporcionalidade. Revista Thesis Juris, São Paulo, vol. 5, n², 2016. Disponível em: http://www.revistartj.org.br/ojs/index.php/rtj/article/view/331. Acesso em: 20 mar. 2020. p. 369389, p. 377.

70 ZOLET, L., MORAIS, F. Inflação dos direitos fundamentais e os vícios e virtudes do princípio da proporcionalidade. p. 377.

71 ZOLET, L., MORAIS, F. Inflação dos direitos fundamentais e os vícios e virtudes do princípio da proporcionalidade. p. 385.

72 ZOLET, L., MORAIS, F. Inflação dos direitos fundamentais e os vícios e virtudes do princípio da proporcionalidade. p. 386.

73 LUHMANN, Niklas. Los derechos fundamentales como instituición: aportación a la sociologia política. p. 329. 
GUALTIERI, André. O problema da inflação de direitos: causas e riscos. Revista Eletrônica Direito e Política, Programa de Pós-Graduação Stricto Sensu em Ciência Jurídica da UNIVALI, Itajaí, v.16, n.1, $1^{\circ}$ quadrimestre de 2021. Disponível em: www.univali.br/direitoepolitica - ISSN 1980-7791

interesses triviais a qualidade de direitos, seja no sentido de gerar um processo de incessante proliferação de direitos e de judicialização de vidas, como ocorre no Brasil. O princípio da proporcionalidade, em especial, exerce um papel importante quando se trata de inflação de direitos pela atividade do poder judiciário.

A inflação de direitos é um problema por várias razões. 1) Ela compromete a distinção entre o Direito e os demais sistemas como a moral e a política. A condição para que o direito possa ser considerado um sistema é que haja uma fronteira definida, que permita dizer o que está dentro e o que está fora, ou seja, o que é direito e o que não é direito. Se potencialmente qualquer aspecto da vida pode se tornar um direito, essa distinção deixa de ser possível. 2) Ela coloca o sistema do direito em perigo, pelo risco de não conseguir se adaptar a tantos novos elementos que são constantemente nele introduzidos. Seria necessário investigar até que ponto é possível introduzir transformações no direito sem colocá-lo em perigo. 3) Ela arruína o valor simbólico da dignidade humana, que é o que realmente merece ser protegido incondicionalmente. Se tudo pode se tornar um direito, fica difícil ver o que realmente deve ser protegido. Se há cada vez mais direitos, se torna normal que eles não sejam observados. Tudo isso justificaria a necessidade de limitação desse processo inflacionário.

De um lado, o risco da inflação de direitos é que ela atue como um buraco negro que suga tudo para dentro de si, o que produziria a autoanulação do Direito. Por outro lado, quando essa inflação diz respeito aos direitos fundamentais, é possível criticá-los por degradar os próprios direitos, de fato, fundamentais. Daí a necessidade, segundo alguns autores anteriormente citados de delimitar o sentido desses direitos, a fim de encontrar os direitos verdadeiros, ou seja, aquilo que realmente merece ser protegido.

Por fim, o problema da inflação dos direitos nos leva ainda a uma questão anterior, mais profunda, porque tem a ver com o próprio fundamento do pensamento jurídico moderno, isto é, a autonomia individual, a partir da qual os direitos passam a ser pensados como um meio para o desenvolvimento da própria personalidade do sujeito. 
GUALTIERI, André. O problema da inflação de direitos: causas e riscos. Revista Eletrônica Direito e Política, Programa de Pós-Graduação Stricto Sensu em Ciência Jurídica da UNIVALI, Itajaí, v.16, n.1, 10 quadrimestre de 2021. Disponível em: www.univali.br/direitoepolitica - ISSN 1980-7791

\section{REFERÊNCIAS DAS FONTES CITADAS}

BARRETO, Vicente de Paulo. O fetiche dos direitos humanos. Porto Alegre: Livraria do Advogado Editora, 2010.

BARROSO, Luís Roberto. Judicialização, ativismo judicial e legitimidade democrática. (Syn)Thesis, Rio de Janeiro, vol. 5, n 1, 2012. Disponível em: https://www.e-publicacoes.uerj.br/index.php/synthesis/article/view/7433/5388.

Acesso em: 28 abr. 2020. p. 23-32.

BOBBIO, Norberto. A era dos direitos. Rio de Janeiro: Campus, 1992.

BRANCO, Paulo Gustavo Gonet; MENDES, Gilmar Ferreira. Curso de direito constitucional. 11 ed. São Paulo: Saraiva, 2016.

BRASIL. Supremo Tribunal Federal. Ação de descumprimento de preceito fundamental 54. Relator: Min. Marco Aurélio, 12 de abril de 2012. Disponível em: http://redir.stf.jus.br/paginadorpub/paginador.jsp?docTP=TP\&docID $=3707334$.

Acesso em: 25 abr. 2020.

Supremo Tribunal Federal. Ação Direta de Inconstitucionalidade 4.424. Relator: Min. Marco Aurélio, 9 de fevereiro de 2012. Disponível em: http://redir.stf.jus.br/paginadorpub/paginador.jsp?docTP=TP\&docID=6393143.

Acesso em: 25 abr. 2020.

. Supremo Tribunal Federal. Habeas Corpus 124.306. Relator: Min. Roberto Barroso, 9 de agosto de 2016. Disponível em: http://redir.stf.jus.br/paginadorpub/paginador.jsp?docTP=TP\&docID=12580345. Acesso em: 25 abr. 2020.

[ [Constituição (1988)]. Constituição da República Federativa do Brasil de 1988. Brasília, DF: Presidência da República, [2020]. Disponível em: http://www.planalto.gov.br/ccivil 03/constituicao/constituicao.htm. Acesso em: 14 abr. 2020.

DENEEN, Patrick J. Why liberalism failed. New Haven: Yale University Press, 2018.

DOUZINAS, Costas. The end of human rights: critical legal thought at the turn of the century. Oxford: Hart Publishing, 2000.

EUROPA. [Convenção (1950)]. Convenção europeia dos direitos do homem. Disponível em: https://www.echr.coe.int/Documents/Convention POR.pdf. Acesso em: 14 abr. 2020.

Corte Europeia de Direitos Humanos. Case of Hatton and others v. the United Kingdom. Application no. 36022/97, 8, de julho de 2003. Disponível em:

https://hudoc.echr.coe.int/app/conversion/pdf/?library=ECHR\&id=00161188\&file name $=001-61188$.pdf\&TID=soudeazyxk. Acesso em: 28 abr. 2020. 
GUALTIERI, André. O problema da inflação de direitos: causas e riscos. Revista Eletrônica Direito e Política, Programa de Pós-Graduação Stricto Sensu em Ciência Jurídica da UNIVALI, Itajaí, v.16, n.1, $1^{\circ}$ quadrimestre de 2021. Disponível em: www.univali.br/direitoepolitica - ISSN 1980-7791

. Corte Europeia de Direitos Humanos. Case of S. and Marper v. the United Kingdom. Applications nos. 30562/04 and 30566/04, 4, de dezembro de 2008.2 Disponível em: https://hudoc.echr.coe.int/app/conversion/docx/pdf?library=ECHR\&id =00190051\&filename $=$ CASE $\% 200 F \% 20$ S. $\% 20$ AND $\% 20$ MARPER $\% 20 \mathrm{~V} . \% 20$ THE $\% 20 \mathrm{U}$ NITED\%20KINGDOM.pdf. Acesso em: 28 abr. 2020.

FERRAZ JR., Tercio Sampaio. Introdução ao estudo do direito: técnica, decisão, dominação. 2 ed. São Paulo: Atlas, 1994.

FERREIRA FILHO, Manoel Gonçalves. Aspectos do direito constitucional contemporâneo. São Paulo: Saraiva, 2003.

FRANÇA. [Declaração de direitos do homem e do cidadão (1789)]. Disponível em: http://www.direitoshumanos.usp.br/index.php/Documentos-anteriores$\%$ C3\%A0-cria\%C3\%A7\%C3\%A3o-da-Sociedade-das-Na\%C3\%A7\%C3\%B5esat\%C3\%A9-1919/declaracao-de-direitos-do-homem-e-do-cidadao-1789.html. Acesso em: 28 fev. 2020.

GLENDON, Mary Ann; KAPLAN, Seth D. Renewing human rights. First Things. Fev. 2019.2 Disponível em: https://www.firstthings.com/article/2019/02/renewing-human-rights. Acesso em: 20 mar. 2020.

GUERRA FILHO, Willis Santiago. O conhecimento imaginário do direito. 1 ed. Curitiba: Editora Prismas, 2017.

HERRERO, Francisco Javier. Estudos de ética e filosofía da religião. São Paulo: Loyola, 2006.

HOBBES, Thomas. Leviatã: ou matéria, forma e poder de um Estado eclesiástico e civil. São Paulo: Edipro, 2015.

HUNT, Lynn. A invenção dos direitos humanos: uma história. São Paulo: Companhia das Letras, 2009.

HUSCROFT, Grant. Proportionality and the relevance of interpretation. In: HUSCROFT, Grant; MILLER, Bradley W.; WEBBER, Grégoire. Proportionality and the Rule of Law: rights, justification, reasoning. Cambridge: Cambridge University Press, 2014. p. 186-202.

IGNATIEFF, Michael. Human rights as idolatry. THE TANNER LECTURES ON HUMAN VALUES, 2000. Disponível em: https://tannerlectures.utah.edu/ documents/a-to-z/i/Ignatieff 01.pdf. Acesso em: 28 abr. 2020.

LILLA, Mark. The stillborn god: religion, politics and the modern west. New York: Vintage Books, 2007. 
GUALTIERI, André. O problema da inflação de direitos: causas e riscos. Revista Eletrônica Direito e Política, Programa de Pós-Graduação Stricto Sensu em Ciência Jurídica da UNIVALI, Itajaí, v.16, n.1, $1^{\circ}$ quadrimestre de 2021. Disponível em: www.univali.br/direitoepolitica - ISSN 1980-7791

LUHMANN, Niklas. El Derecho de la Sociedad. versão 5.0, de 13/01/2003; formatação eletrônica - João Protásio Farias Domingues de Vargas e Marjorie Corrêa Marona, 2003.

Introdução à teoria dos sistemas. Petrópolis: Vozes, 2009.

. Los derechos fundamentales como instituición: aportación a

la sociologia política. México, D.F.: Universidad Iberoamericana, 2010.

MÖLLER, Kai. The global model of constitutional rights. Oxford: Oxford University Press, 2012.

. Proportionality and rights inflation. In: HUSCROFT, Grant; MILLER, Bradley W.; WEBBER, Grégoire. Proportionality and the Rule of Law: rights, justification, reasoning. Cambridge: Cambridge University Press, 2014. p. 155172.

RAWLS, John. O liberalismo político. 2. ed. São Paulo: Editora Ática, 2000.

RAZ, Joseph. Human rights without foundations. In: BESSON, Samantha; TASIOULAS, John. The philosophy of international law. Oxford: Oxford University Press, 2010. p. 321-348.

TUCK, Richard. Natural rights theories: their origin and development. Cambridge: Cambridge University Press, 1998.

ZOLET, L., MORAIS, F. Inflação dos direitos fundamentais e os vícios e virtudes do princípio da proporcionalidade. Revista Thesis Juris, São Paulo, vol. 5, $\mathrm{n}^{0} 2$, 2016. Disponível em: http://www.revistartj.org.br/ojs/index.php/rtj/article/view/331. Acesso em: 20 mar. 2020. p. 369-389.

RECEBIDO EM: MAI/2020

APROVADO EM: AGO/2020 